\title{
Cartilage Induction from Mouse Mesenchymal Stem Cells in High-density Micromass Culture
}

Takashi lezaki ${ }^{1,2}$, Kazuya Fukasawa1, Takanori Yamada1, Manami Hiraiwa1, Katsuyuki Kaneda ${ }^{1}$ and Eiichi Hinoi ${ }^{1, *}$

${ }^{1}$ Laboratory of Molecular Pharmacology, Division of Pharmaceutical Sciences, Kanazawa University Graduate School, Kanazawa, Ishikawa, 920-1192, Japan; ${ }^{2}$ Venture Business Laboratory, Organization of Frontier Science and Innovation, Kanazawa University, Kanazawa, Ishikawa, 920-1192, Japan *For correspondence: hinoi@p.kanazawa-u.ac.jp

[Abstract] Mesenchymal stem cells have the ability to differentiate into multiple lineages, including adipocytes, osteoblasts and chondrocytes. Mesenchymal stem cells can be induced to differentiate into chondrocytes in extracellular matrices, such as alginate or collagen gel. Mesenchymal stem cells in a cell pellet or micromass culture can be also induced to form cartilages in a defined medium containing chondrogenic cytokines, such as transforming growth factor- $\beta$ (TGF- $\beta$ ). Here, we describe a simple method to form cartilage by seeding mesenchymal cells derived from limb-bud cells at high cell density. First, we dissected the limb buds from embryonic mice (embryonic day 12.5) and digested them with enzymes (dispase and collagenase). After filtration using a cell strainer, we seeded the cells at high density. Unlike other methods, the method described here is simple and does not require the use of specialized equipment, expensive materials or complex reagents.

Keywords: Chondrocytes, Mesenchymal cell, Micromass culture, Cartilage, Endochondral ossification

[Background] Mesenchymal cells differentiate into skeletal elements by forming a cartilaginous nodule, which induces bone formation through endochondral ossification in the vertebral column and long bones (Karsenty et al., 2009). Endochondral ossification is required for proper skeletal development during embryogenesis and has been recently demonstrated to be involved in the bone regeneration and joint diseases postnatally (Kawaguchi, 2008). Mesenchymal cells could be used as a regenerative therapy for these diseases. To study the mechanisms regulating endochondral skeletal development, we have examined high-density micromass cultures of embryonic limb-bud mesenchymal cells (Gay and Kosher, 1984; lezaki et al., 2018). The in vitro chondrogenic cell culture system is useful for the analysis cartilage nodule formation that results from the condensation of mesenchymal cells and differentiation into chondrocytes.

Several methods have been developed to generate cartilage from mesenchymal cells. Mesenchymal cells in cell pellet or micromass culture can be induced to form cartilage in chondrogenic medium containing cytokines such as transforming growth factor- $\beta$ (TGF- $\beta$ ) (Sekiya et al., 2002). Mesenchymal cells have also been induced to differentiate into chondrocytes in extracellular matrices such as alginate or collagen gel (Xu et al., 2008). Although these methods are effective to analyze chondrogenesis, they can be time consuming and expensive because they require complex reagents and equipment.

For this reason, we have developed a culture method to form cartilage from mesenchymal cells using 
a very simple method. We induced the differentiation of cells harvested from mouse limb buds (embryonic day 12.5) in high-density micromass culture and induced the cells to form cartilage nodules in growth medium without chondrogenic cytokines. In comparison to other methods, the method described here is simple and does not require specialized equipment, expensive materials or complex reagents. This method could be really useful for reducing the cost and complexity of the procedure.

\section{Materials and Reagents}

1. Pipette tips (RIKAKEN, catalog numbers: RST 481SCV, RST 4820YV, RST 4810BV)

2. $1.5 \mathrm{ml}$ tube (WATSON, catalog number: 131-815C)

3. Cell strainer (Corning, catalog number: 352235 )

4. 4-well cell culture plate (Thermo Fisher Scientific, catalog number: 176740)

5. Syringe-driven filter unit (Millipore, catalog number: SLGV033RS)

6. Filter paper (ADVANTEC, catalog number: 00011090)

7. E12.5 Embryo mice (C57BL/6J)

8. D-MEM/Ham's F-12 (Wako, catalog number: 048-29785)

9. Dispase (Gibco, catalog number: 17105-041)

10. Collagenase (Wako, catalog number: 034-22363)

11. FBS (Sigma, NRE-172012)

12. L(+)-Ascorbic Acid (Wako, catalog number: 016-04805)

13. Paraformaldehyde (PFA) (Wako, catalog number: 162-16065)

14. Sodium Hydroxide (Wako, catalog number: 198-13765)

15. Acetic acid (Wako, catalog number: 017-00251)

16. 10x PBS(-) (Wako, catalog number: 314-90185)

17. Alcian Blue 8GX powder (Sigma, catalog number: A5268-25G)

18. Enzyme solution (see Recipes)

19. L(+)-Ascorbic acid stock solution (see Recipes)

20. Chondrogenic medium (see Recipes)

21. $8 \%$ PFA stock solution (see Recipes)

22. $1 \%$ acetic acid solution (see Recipes)

23. Alcian blue solution (see Recipes)

\section{Equipment}

1. Pipettes (Glison, catalog numbers: F144802, F123615, F123602)

2. Microtube rotator (AS ONE, catalog number: MTR-103)

3. $\mathrm{CO}_{2}$ incubator (SANYO, model: MCO-17AIC)

4. High speed refrigerated microcentrifuge (TOMY, model: MX-307)

5. Automated cell counter (Bio-Rad, model: TC-20) 
6. Microscope (Kyence, model: BZ-9000)

\section{Software}

1. BZ-2 application (Keyence)

2. ImageJ (NIH, https://imagej.nih.gov/ii/)

\section{Procedure}

A

A

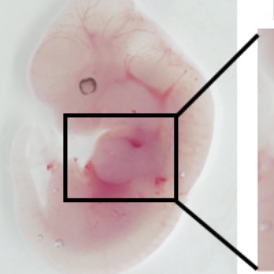

B

E12.5

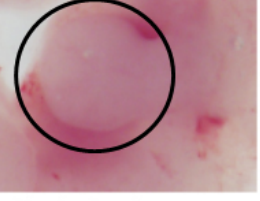

Dissection

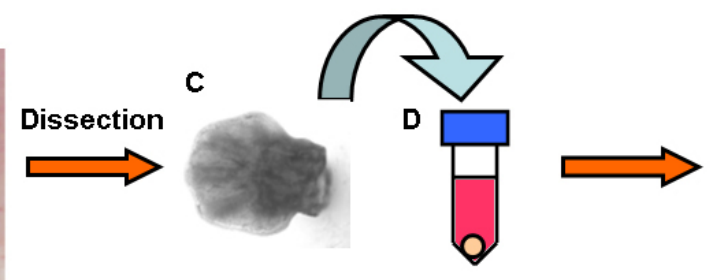

C

mouse embryo

Limb bud

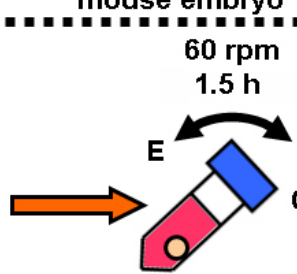

$0.1 \%$ Dispase

$0.1 \%$ Collagenase at $37^{\circ} \mathrm{C}$

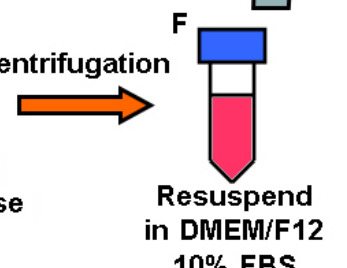

G

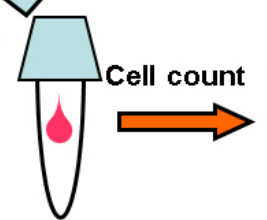

Filter with

Cell strainer

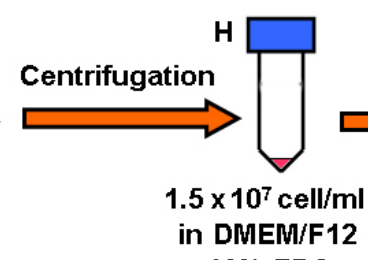

$10 \%$ FBS

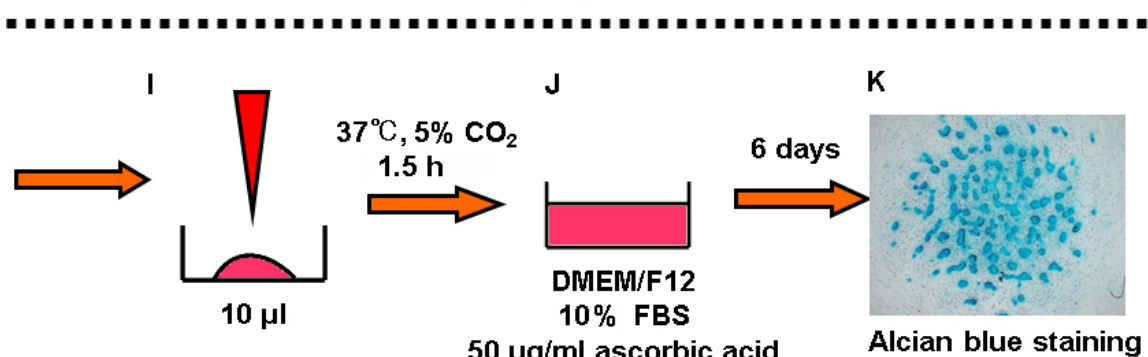

Figure 1. Summary of experimental procedure. In brief: A-C. Dissect the limb buds from embryonic mice. D-E. Digested them with enzymes (dispase and collagenase). F-I. Seed the cells at high density. J. Add the chondrogenic medium and incubate for 6 days. K. Alcian blue staining.

A. Preparation of the cells

1. Dissect the limb buds from mouse embryonic day 12.5 (the part surrounded by circle in Figure 1B). One limb bud is enough to induce 2 or 3 wells of cartilage (Figures $1 \mathrm{~A}-1 \mathrm{C}$ ).

2. Collect the limb buds in a $1.5 \mathrm{ml}$ tube and add $1 \mathrm{ml}$ enzyme solution $(0.1 \%$ Dispase, $0.1 \%$ Collagenase in D-MEM/Ham's F-12) (Figure 1D). 
3. Rotate the tube at $60 \mathrm{rpm}$ on a microtube rotator (AS ONE) for $1.5 \mathrm{~h}$ at $37^{\circ} \mathrm{C}$ (Figure 1E).

4. Centrifuge the tube for $5 \mathrm{~min}$ at $300 \times \mathrm{g}$ and resuspend the cells in $1 \mathrm{ml} \mathrm{D}-\mathrm{MEM} / \mathrm{Ham} \mathrm{s} \mathrm{F}-12$ (Figure 1F).

5. Apply the cell suspension to a $40 \mu \mathrm{m}$ cell strainer placed in a $5 \mathrm{ml}$ round bottom tube and measure the cell density using an automated cell counter (Bio-Rad) (Figure 1G).

B. Cartilage formation

1. Centrifuge the tube for $5 \mathrm{~min}$ at $300 \times \mathrm{g}$ and resuspend the cells in D-MEM/Ham's F-12 containing $10 \%$ FBS to adjust the cell density to $1.5 \times 10^{7} \mathrm{cells} / \mathrm{ml}$ (Figure $1 \mathrm{H}$ ).

2. Place a $10 \mu \mathrm{l}$ droplet in 4-well culture plate and incubate the cells in the $\mathrm{CO}_{2}$ incubator for $1.5 \mathrm{~h}$ (Figure 11).

3. Add the $500 \mu \mathrm{l}$ chondrogenic medium (D-MEM/Ham's F-12 containing $10 \% \mathrm{FBS}$ and $50 \mu \mathrm{g} / \mathrm{ml}$ $\mathrm{L}$-ascorbic acid) with care not to disrupt the droplet and incubate in the $\mathrm{CO}_{2}$ incubator (Figure $1 \mathrm{~J})$.

4. Change the medium every 2 days and incubate for 6 days.

C. Alcian blue staining (Figure $1 \mathrm{~K}$ )

1. Fix the cells in $500 \mu \mathrm{l} 4 \%$ PFA for $10 \mathrm{~min}$ and wash the cells twice using Milli-Q water.

2. Add $500 \mu \mathrm{l} 1 \%$ acetic acid for $5 \mathrm{~min}$ and replace acetic acid by $500 \mu \mathrm{l}$ Alcian blue solution for 30 $\min$.

3. Wash the cells with $500 \mu \mathrm{l} 1 \%$ acetic acid and wash twice using Milli-Q water.

4. Image the stained cells using optical microscope (Figure 2).

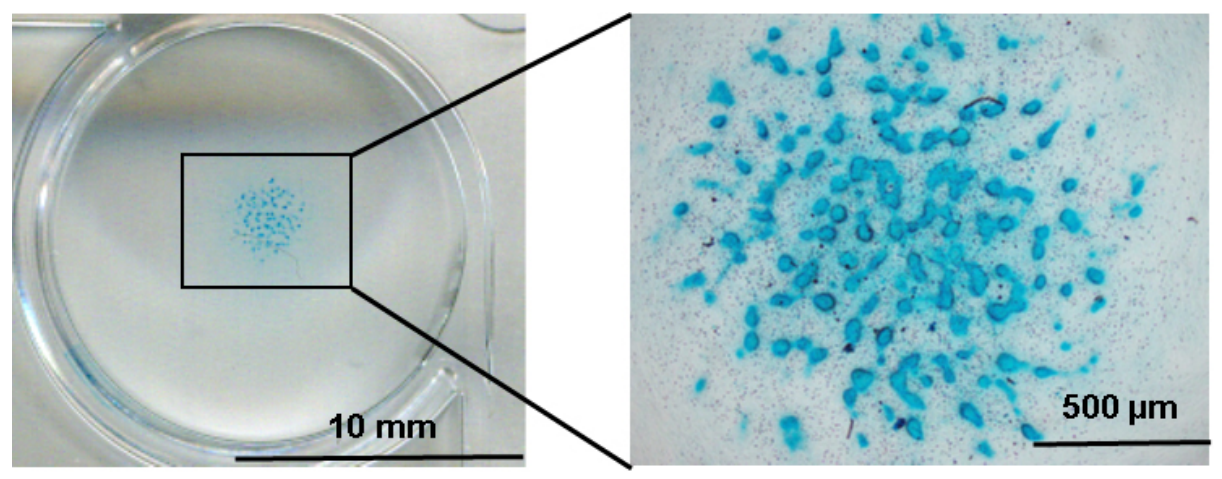

Figure 2. Alcian blue staining

\section{Data analysis}

Alcian blue stained areas were measured with ImageJ software (Abramoff et al., 2004). Appropriate statistical analysis should be carried out on the obtained data. 


\section{Recipes}

1. Enzyme solution

Dissolve the dispase (Gibco) and collagenase (Wako) (0.1\% w/v each) in D-MEM/Ham's F-12 (Wako) and filter with a $0.22 \mu \mathrm{m}$ syringe filter (Millipore)

2. $\mathrm{L}(+)$-Ascorbic acid stock solution

Dissolve the ascorbic acid (Wako) $(50 \mathrm{mg} / \mathrm{ml})$ in PBS(-) and filter with syringe filter (Millipore)

3. Chondrogenic medium

D-MEM/Ham's F-12 (Wako) containing 10\% FBS (Sigma) and $50 \mu \mathrm{g} / \mathrm{ml}$ L-ascorbic acid

4. $8 \%$ PFA stock solution

Add the $40 \mathrm{~g}$ of PFA (Wako) in $400 \mathrm{ml}$ of hot Milli-Q water $\left(60^{\circ} \mathrm{C}\right.$ ) and add $50 \mu \mathrm{l}$ of $10 \mathrm{~N} \mathrm{NaOH}$ (Wako), continue to stir until PFA dissolves

Add $50 \mathrm{ml}$ of $10 x$ PBS(-) and adjust to final volume of $500 \mathrm{ml}$

5. $1 \%$ acetic acid solution

Add $1 \mathrm{ml}$ of acetic acid (Wako) to $99 \mathrm{ml}$ of Milli-Q water

6. Alcian blue solution

Dissolve $1 \mathrm{~g}$ of Alcian blue $8 \mathrm{GX}$ (Sigma) in $100 \mathrm{ml}$ of $3 \%$ acetic acid solution (Wako) and filter with filter paper (ADVANTEC)

\section{Acknowledgments}

This work was supported in part by the Japan Society for the Promotion of Science (16H05131 and 17KT0051 to E.H.), the Japan Agency for Medical Research and Development (17824969 to E.H.).

\section{Competing interests}

The authors declare no conflict of interest.

\section{Ethics}

The study protocol meets the guidelines of the Japanese Pharmacological Society and was approved by the Committee for Ethical Use of Experimental Animals at Kanazawa University, Kanazawa, Japan.

\section{References}

1. Abramoff, M. D., Magalhães, P. J. and Ram, S. J. (2004). Image processing with ImageJ. Biophotonics International 11(7): 36-42.

2. Gay, S. W. and Kosher, R. A. (1984). Uniform cartilage differentiation in micromass cultures 
prepared from a relatively homogeneous population of chondrogenic progenitor cells of the chick limb bud: effect of prostaglandins. J Exp Zool 232(2): 317-326.

3. lezaki, T., Horie, T., Fukasawa, K., Kitabatake, M., Nakamura, Y., Park, G., Onishi, Y., Ozaki, K., Kanayama, T., Hiraiwa, M., Kitaguchi, Y., Kaneda, K., Manabe, T., Ishigaki, Y., Ohno, M. and Hinoi, E. (2018). Translational control of Sox9 RNA by mTORC1 contributes to skeletogenesis. Stem Cell Reports 11(1): 228-241.

4. Karsenty, G., Kronenberg, H. M. and Settembre, C. (2009). Genetic control of bone formation. Annu Rev Cell Dev Biol 25: 629-648.

5. Kawaguchi, H. (2008). Endochondral ossification signals in cartilage degradation during osteoarthritis progression in experimental mouse models. Mol Cells 25(1): 1-6.

6. Sekiya, I., Vuoristo, J. T., Larson, B. L. and Prockop, D. J. (2002). In vitro cartilage formation by human adult stem cells from bone marrow stroma defines the sequence of cellular and molecular events during chondrogenesis. Proc Natl Acad Sci U S A 99(7): 4397-4402.

7. Xu, J., Wang, W., Ludeman, M., Cheng, K., Hayami, T., Lotz, J. C. and Kapila, S. (2008). Chondrogenic differentiation of human mesenchymal stem cells in three-dimensional alginate gels. Tissue Eng Part A 14(5): 667-680. 